\title{
Área de Proteção Ambiental Rainha das Águas do município de Paraíba do Sul (RJ, Brasil): estudo da cobertura florestal, contingências e manejo
}

\author{
Rainha das Águas Environmental Protection Area in the municipality of Paraíba \\ do Sul (RJ, Brazil): forest cover, contingencies, and management study
}

\section{Mayke do Couto Lima', Sady Júnior Martins da Costa de Menezes"I, Fábio Souto de Almeida ${ }^{\text {III }}$}

\begin{abstract}
Resumo
O objetivo deste trabalho foi estudar a cobertura florestal da Área de Proteção Ambiental Rainha das Águas (APA Rainha das Águas) e apontar as suas contingências e potencialidades, visando embasar o seu futuro plano de manejo. A APA abrange todo o Município de Paraíba do Sul, Estado do Rio de Janeiro. Foi realizada uma revisão bibliográfica e trabalhos de campo para obter as contingências, potencialidades e características da APA, incluindo a caracterização visual da vegetação para validação da análise da cobertura florestal realizada com as Bases Cartográficas RJ (2010) e Contínua RJ-25 (2018) no Datum SIRGAS 2000.Foram detectados 612 fragmentos florestais e a porcentagem da área da APA coberta por florestas foi de $23,01 \%$. Dentre os problemas identificados na APA estão o desmatamento e as queimadas, que provocaram a redução e fragmentação das florestas nativas. Também são contingências relevantes a caça, a pesca predatória, as construções em locais inapropriados, a agropecuária e a silvicultura realizadas de forma imprópria, a poluição por efluentes líquidos, a introdução de espécies exóticas, a falta de conhecimento da população sobre a APA e a escassez de recursos financeiros. Dentre as ações de manejo necessárias, estão os reflorestamentos, a fiscalização, o planejamento ambiental, o estímulo à adoção de policultivos e práticas agroecológicas, o tratamento de efluentes, informar a população sobre a APA e suas potencialidades, utilização do valor arrecadado com ICMS Ecológico, compensação ambiental e produtos e serviços da APA na gestão da unidade. A educação ambiental deve ser utilizada para minimizar vários problemas identificados. Como potencialidades, cita-se o turismo histórico, ecológico e rural. Ressalta-se a importância da proteção do rio Paraíba do Sul, essencial para o abastecimento público. A partir da implementação dos programas de manejo necessários, a APA pode colaborar efetivamente para o desenvolvimento sustentável do Município de Paraíba do Sul.
\end{abstract}

Palavras-chave: Educação ambiental; Fiscalização; Plano de manejo; Recursos naturais

Gestor Ambiental, Instituto Três Rios, Universidade Federal Rural do Rio de Janeiro, Av. Prefeito Alberto Lavinas, 1847, Centro, CEP 25802-100, Três Rios (RJ), Brasil. Imaike.couto@gmail.com (ORCID: 0000-0002-1540-1574)

II Engenheiro Agrícola e Ambiental, Dr., Professor do Departamento de Ciências do Meio Ambiente, Instituto Três Rios, Universidade Federal Rural do Rio de Janeiro, Av. Prefeito Alberto Lavinas, 1847, Centro, CEP 25802-100, Três Rios (RJ), Brasil. sadymenezes@gmail.com (ORCID: 0000-00026723-7470)

III Engenheiro Florestal, Dr., Professor do Departamento de Ciências do Meio Ambiente, Instituto Três Rios, Universidade Federal Rural do Rio de Janeiro, Av. Prefeito Alberto Lavinas, 1847, Centro, CEP 25802-100, Três Rios (RJ), Brasil. fbio_almeida@yahoo.com.br (ORCID: 0000-0001-6214397X) 


\begin{abstract}
The present study aimed to assess the forest cover of the Rainha das Águas Environmental Protection Area (APA Rainha das Águas) and its contingencies and potentialities, intending to set the bases for a management plan. The APA covers the entire municipality of Paraíba do Sul, state of Rio de Janeiro, Brazil. Through literature review and field activities, we obtained information about the contingencies, potentialities, and characteristics of the APA, including the visual characterization of the vegetation to validate the forest cover analysis, using the Cartographic Bases RJ (2010) and Continuous RJ-25 (2018), in SIRGAS 2000 Datum. We detected 612 forest fragments, with a percentage of forest cover of 23.01\%. Deforestation and forest fires are among the problems identified in the APA, which resulted in the reduction and fragmentation of native forests. Hunting, predatory fishing, improper construction, agriculture and forestry carried out improperly, effluent pollution, species introduction, lack of knowledge of the population about the APA, and scarcity of financial resources are also relevant problems. Among management actions recommended are reforestation, environmental inspection, environmental planning, encouragement of polyculture and agroecological practices, wastewater treatment, dissemination of information about the APA and its potentialities to the population, and use of the amount obtained with Ecological ICMS, environmental compensation, and APA products and services in the management of the protected area. Environmental education should be widely used to minimize several problems. The potentialities of the APA include historical, ecological, and rural tourism. It is crucial to emphasize the importance of protecting the Paraíba do Sul River, which is essential for public water supply. With the implementation of management programs, the APA Rainha das Águas will be able to collaborate effectively for the sustainable development of the municipality of Paraíba do Sul.
\end{abstract}

Keywords: Environmental education; Inspection; Management plan; Natural resources

\title{
Introdução
}

É notável o aumento da degradação do meio ambiente em escala global no último século, em seus variados aspectos, incluindo alterações negativas nos componentes do meio físico e nos ecossistemas naturais, provocando consequências adversas para a sociedade (ALMEIDA et al., 2017). Tais impactos negativos demandam soluções para reduzir e compensar os danos causados e garantir o desenvolvimento econômico e social, sem comprometer a perenidade de recursos naturais essenciais ao ser humano e os serviços ecossistêmicos advindos da biodiversidade (ALMEIDA; VARGAS,2017).As unidades de conservação têm sido adotadas para esse fim, pois colaboram para reduzir e evitar a degradação ambiental, que está entre os fatores que reduzem a diversidade biológica e a disponibilidade de recursos naturais para uso humano (ALMEIDA; VARGAS, 2017).

O patrimônio natural brasileiro é um dos mais relevantes do mundo, sua riqueza se expressa pela elevada diversidade de espécies e altas taxas de endemismo, além da considerável variedade de ecossistemas e a abundância de recursos naturais (ARRUDA; SÁ,2003). No mês de julho de 2000 entrou em vigor no Brasil a Lei Federal $N^{\circ} 9.985$,instituindo o Sistema Nacional de Unidades de Conservação da Natureza (SNUC)com diretrizes para constituir e manejar as unidades de conservação(BRASIL, 2000; ALMEIDA; VARGAS, 2017).

A delimitação de áreas onde a utilização dos recursos naturais será controlada, realizando-se a sua extração de forma sustentável e evitando a sua degradação, pode colaborar para a adequada qualidade de vida das populações atuais e futuras (PRIMACK; RODRIGUES, 2001). Isso vai ao encontro do conceito de desenvolvimento sustentável, no que tange conciliar as atividades produtivas com a manutenção do meio ambiente ecologicamente equilibrado (CARVALHO, 2019). Algumas unidades de conservação possuem esse viés, pois têm o objetivo de disciplinar o uso e a ocupação do solo, claramente buscando o desenvolvimento sustentável (BRASIL, 2000).

Dentre as categorias de unidades de conservação propostas pelo SNUC está a Área de Proteção Ambiental (APA), pertencente ao grupo de unidades de uso sustentável (ALMEIDA; VARGAS, 2017). A Área de Proteção Ambiental deve possuir ocupação antrópica e atributos 
naturais ou culturais relevantes para as populações humanas, sendo flexível quanto à utilização dos recursos naturais e uso do solo, porém com gestão, visando disciplinar a utilização sustentável de seus atributos naturais (BRASIL,2000).

O Bioma Mata Atlântica ocupa expressiva parcela do território brasileiro, incluindo estados que apresentam elevada densidade populacional, existindo assim pressão para a utilização dos seus recursos naturais e, como resultado, o bioma apresenta grande fragmentação dos ecossistemas florestais (RIBEIRO et al., 2011). A destruição de seus ecossistemas terrestres devido às atividades humanas provocou a expressiva redução da sua extensão original, restando apenas $22 \%$ da cobertura originalmente existente de vegetação nativa, com somente $8,5 \%$ dessa cobertura constituindo florestas com mais de 100 ha (MMA, 2019). A despeito da redução da área ocupada pelos seus ecossistemas naturais, estimativas apontam para a existência de importantes recursos naturais e um elevado número de espécies de variados táxons nesse bioma, diversas destas endêmicas da Mata Atlântica (MMA, 2019).Assim, é premente a criação e o manejo eficiente de unidades de conservação da natureza na Mata Atlântica para proporcionar a proteção da diversidade biológica, dos serviços ecossistêmicos e dos recursos naturais, evitando a degradação ambiental e garantindo a capacidade produtiva necessária para o desenvolvimento econômico. Desse modo, as unidades de conservação podem beneficiar as populações melhorando a qualidade de vida (ALMEIDA; VARGAS, 2017).

Nesse sentido, o Município de Paraíba do Sul, no Estado do Rio de Janeiro, criou a APA Rainha das Águas. Paraíba do Sul apresenta uma rica história, ligada ao ciclo do café, à mineração e à inconfidência mineira, possuindo museus e pontos turísticos históricos (ROUSSOULIÉRES, 2015). O município apresenta fontes de águas minerais conhecidas pelo suposto poder curativo, paisagens belas e recursos naturais importantes, incluindo o rio Paraíba do Sul, importante para a geração de energia elétrica, para a manutenção da diversidade biológica local e também para o abastecimento de milhões de pessoas (FERNANDES et al., 2015).Contudo, a APA Rainha das Águas apresenta diversas contingências, incluindo a restrita cobertura florestal, e ainda não possui plano de manejo. Assim, este trabalho teve como objetivo estudar a cobertura florestal da APA Rainha das Águas e apontar as suas contingências e potencialidades. Também foram propostas atividades de manejo para minimizar as contingências identificadas e otimizar as potencialidades da APA, visando embasar o seu futuro plano de manejo. Ressalta-se que as informações presentes neste trabalho também podem contribuir para a gestão de outras unidades de conservação da natureza.

\section{Material e método}

\section{Processos metodológicos}

Realizou-se uma revisão bibliográfica visando à obtenção de informações sobre as características do Município de Paraíba do Sul, sobre as contingências relacionadas ao manejo de unidades de conservação da natureza e a respeito de programas de manejo para unidades de conservação. A bibliografia foi obtida através de websites contendo bases de dados com publicações científicas, sendo também consultados websites institucionais e trabalhos de conclusão de curso. Atividades de campo foram realizadas para registro de características da APA Rainha das Águas, por meio da verificação in loco -observação visual e obtenção de fotografias do estrato vegetacional do local (pasto, floresta, arbustos, culturas agrícolas e florestais, etc.) para fins de verificação quanto às informações levantadas pelos dados secundários obtidos no Instituto Brasileiro de Geografia e Estatística (IBGE), Base Cartográfica Contínua RJ-25 (versão 2018).A Secretaria Municipal do Ambiente e Desenvolvimento Agrário do Município de Paraíba do Sul foi consultada para o levantamento de contingências e a obtenção de demais informações. Buscou-se percorrer todos os distritos de Paraíba do Sul, com foco em locais com atributos 
que gerem ameaças aos recursos naturais e a qualidade ambiental na APA, como aglomerados urbanos, áreas agrícolas e industriais, além de visitar locais com potencial turístico, seja turismo histórico, rural ou ecológico. O diagnóstico ambiental incluiu o levantamento de informações sobre as características socioeconômicas e do meio físico, metodologia baseada em Bento (2014). Também foram obtidas as potencialidades a serem utilizadas para que a APA alcance os seus objetivos de forma eficaz.

Para a análise das feições da paisagem da APA utilizou-se a Base Cartográfica Contínua RJ-25 (versão 2018) e Base Cartográfica versão 2010, disponíveis no sítio eletrônico do IBGE com o formato vetorial no Datum SIRGAS 2000, como objetivo de obter shapefiles da delimitação dos fragmentos florestais existentes na APA e também as seguintes feições da paisagem: pastagens; áreas agrícolas; vegetação arbustiva; solo e rochas expostas; área edificada; e massas d'água. Também foram obtidos os limites do Município de Paraíba do Sul e de seus distritos: Paraíba do Sul; Salutaris; Inconfidência; e Werneck (ROUSSOULIÉRES, 2015). A análise foi realizada com o software ArcGIS, versão 10.2.1. Procedeu-se a extração dos fragmentos florestais para cada um dos distritos através da ferramenta Clip. Foi confeccionado um mapa de uso e cobertura do solo para a APA.

A partir da tabela de atributos dos arquivos shapefile foram obtidas métricas da paisagem, como a área dos fragmentos florestais, o seu perímetro e a distância para o remanescente florestal mais próximo, sendo considerada como uma medida do nível de isolamento de cada fragmento florestal. Para a obtenção da área e do perímetro dos fragmentos florestais da APA foi utilizada a função Calculate Geometry. Foi realizado o cálculo do índice de circularidade, sendo obtidos valores que variam de 0 até 1 , onde valores mais próximos de 1 indicam que o remanescente florestal se aproxima da forma de um círculo (BORGES et al., 2004; SILVÉRIO NETO, 2014). Para o cálculo, foram empregadas as seguintes equações:

$$
\begin{aligned}
& I C=\sqrt{\frac{A 1}{A 2}} \\
& A 2=\pi R^{2} \\
& R=\frac{P}{2 \pi}
\end{aligned}
$$

onde: $\mathrm{IC}$ = índice de circularidade; $\mathrm{P}$ = perímetro do remanescente florestal; $\mathrm{A} 1$ = área do remanescente florestal avaliado; $\mathrm{A} 2$ = área de um círculo com perímetro igual ao do remanescente florestal avaliado; $\mathrm{R}$ = raio do círculo (BORGES et al.,2004; SILVÉRIO NETO, 2014).

Foram observadas divergências entre os dados obtidos no sítio eletrônico do IBGE nos arquivos em shapefiles, pois os limites dos distritos não coincidiram com a delimitação do município como um todo, o que pode ser atribuído à diferença na data da elaboração das malhas digitais utilizadas. Foi acessado através da Prefeitura Municipal de Paraíba do Sul/RJ o decreto de criação da APA do ano de 2015 e o arquivo em formato $\mathrm{kmz}$ constando os limites da unidade de conservação. Para corrigir tais irregularidades foram realizadas operações de edição dos dados e arquivos digitais em ambiente geoes pacial (uso da ferramenta Editor no ArcGIS), confrontando-as espacialmente pelo uso do programa de geoprocessamento. Após análise espacial e sobreposição das mesmas, utilizou-se dos recursos de agrupamento das novas feições editadas (duas ou mais áreas cujos limites sobrepuseram ou que compartilharam um limite em comum foram juntadas em uma área) unindo-as em uma feição de parte única (uso da ferramenta Dissolve no ArcGIS) para a correção do traçado dos limites dos distritos. Os procedimentos executados tornaram a nova base de dados editada e corrigida condizente com os limites do município, tendo em vista que o limite municipal utilizado é o mais recente (base de dados RJ-25 de 2018), enquanto os limites mais recentes dos distritos disponíveis no sítio eletrônico do IBGE são datados de 2010. 
Por fim, após a análise das características da APA e dos problemas observados, foi realizada a proposição de medidas de manejo para minimizar os problemas detectados. Também foram propostas atividades de manejo para a utilização e otimização das potencialidades da APA.

\section{Área de Proteção Ambiental Rainha das Águas}

A APA Rainha das Águas foi criada através do Decreto Municipal N. 1.323 de 2015 (PARAÍBA DO SUL, 2015). A delimitação da APA é a mesma do Município de Paraíba do Sul $\left(582,21 \mathrm{~km}^{2}\right)$ e está localizado na Mesorregião Centro-Sul Fluminense, Estado do Rio de Janeiro (Figura 1). Estima-se que o município apresente 44.045 habitantes e densidade demográfica de $70,77 \mathrm{hab} / \mathrm{km}^{2}$ (IBGE, 2019).

A Floresta Estacional Semidecidual da Mata Atlântica é a vegetação nativa da maior parcela da APA Rainha das Águas (SILVÉRIO NETO, 2014). O clima na APA Rainha das Águas é o subtropical úmido e subúmido, com variação da precipitação pluviométrica entre $1300 \mathrm{~mm}$ a $1600 \mathrm{~mm}$ e da temperatura do ar média entre $20^{\circ} \mathrm{C}$ e $24^{\circ} \mathrm{C}$ (SILVÉRIO NETO, 2014). Em relação às águas superficiais, é necessário salientar que o município se encontra inserido na bacia hidrográfica do rio Paraíba do Sul (FERNANDES et al., 2015).

A produção agrícola é diversificada, proporcionada em grande parte por pequenos produtores familiares, ocorrendo nos últimos anos um aumento na adoção da prática de produção de alimentos orgânicos no Município de Paraíba do Sul (CARDOSO; GARRIDO, 2014; ESTRADA et al., 2019). ESTRADA et al. (2019) observaram propriedades com cultivo orgânico de alimentos com policultivos contendo até 42 espécies de plantas. Destacam-se entre as plantas cultivadas a cana-de-açúcar, a mandioca e o milho, entre outras culturas (IBGE, 2019). Em relação à pecuária, a estimativa do rebanho de bovinos para o ano de 2018 foi de 34.440 cabeças, além de 1563 equinos, expressivo número de galináceos e vários rebanhos de outros animais (IBGE, 2019). O município apresenta empresas do setor alimentício, como fábricas de refrigerantes e de doces, do setor de alumínio, ceramista, química, embalagens, têxtil, entre outros.

As Áreas de Proteção Ambiental estão intimamente relacionadas com o desenvolvimento sustentável e a melhoria da qualidade de vida da população. Essa categoria de unidade de conservação é utilizada para áreas protegidas com atributos naturais e culturais relevantes para a população, com certo grau de ocupação humana e possuem áreas geralmente extensas, onde se deve buscar disciplinar o processo de ocupação buscando a sustentabilidade ambiental (BRASIL, 2000). A APA está incluída no grupo de unidades de uso sustentável, ou seja, permite a interferência humana desde que seja feita de forma sustentável, respeitando a capacidade regenerativa dos elementos naturais (BRASIL, 2000). Pode-se mencionar que a APA é uma categoria de unidade de conservação pouco restritiva quanto ao uso dos recursos naturais e às possibilidades de abrigar empreendimentos, quando comparada a outras categorias de unidades de conservação.

Os objetivos da APA Rainha das Águas são: "I - Preservar a beleza cênica e ecológica do Município de Paraíba do Sul; II - Proteger ecossistemas com grande potencial para oferecer oportunidade de visitação, aprendizagem, interpretação, educação, pesquisa, recreação, inspiração, relaxamento e atividades espirituais ambientalmente compatíveis; III - Estimular o turis mo e a geração de emprego e renda" (PARAÍBA DO SUL, 2015).A denominação da unidade de conservação se deu em função da presença das fontes naturais de água mineral expressivamente conhecidas na região por apresentar concentrações incomuns de diferentes elementos (água magnesiana, ferruginosa e alcalina). Tais fontes estão presentes no Parque das Águas Minerais Salutares. 


\section{Figura 1 - Localização do município de Paraíba do Sul (vermelho) no Estado do Rio de Janeiro, Brasil}

Figure 1 - Location of the municipality of Paraíba do Sul (red) in the state of Rio de Janeiro, Brazil

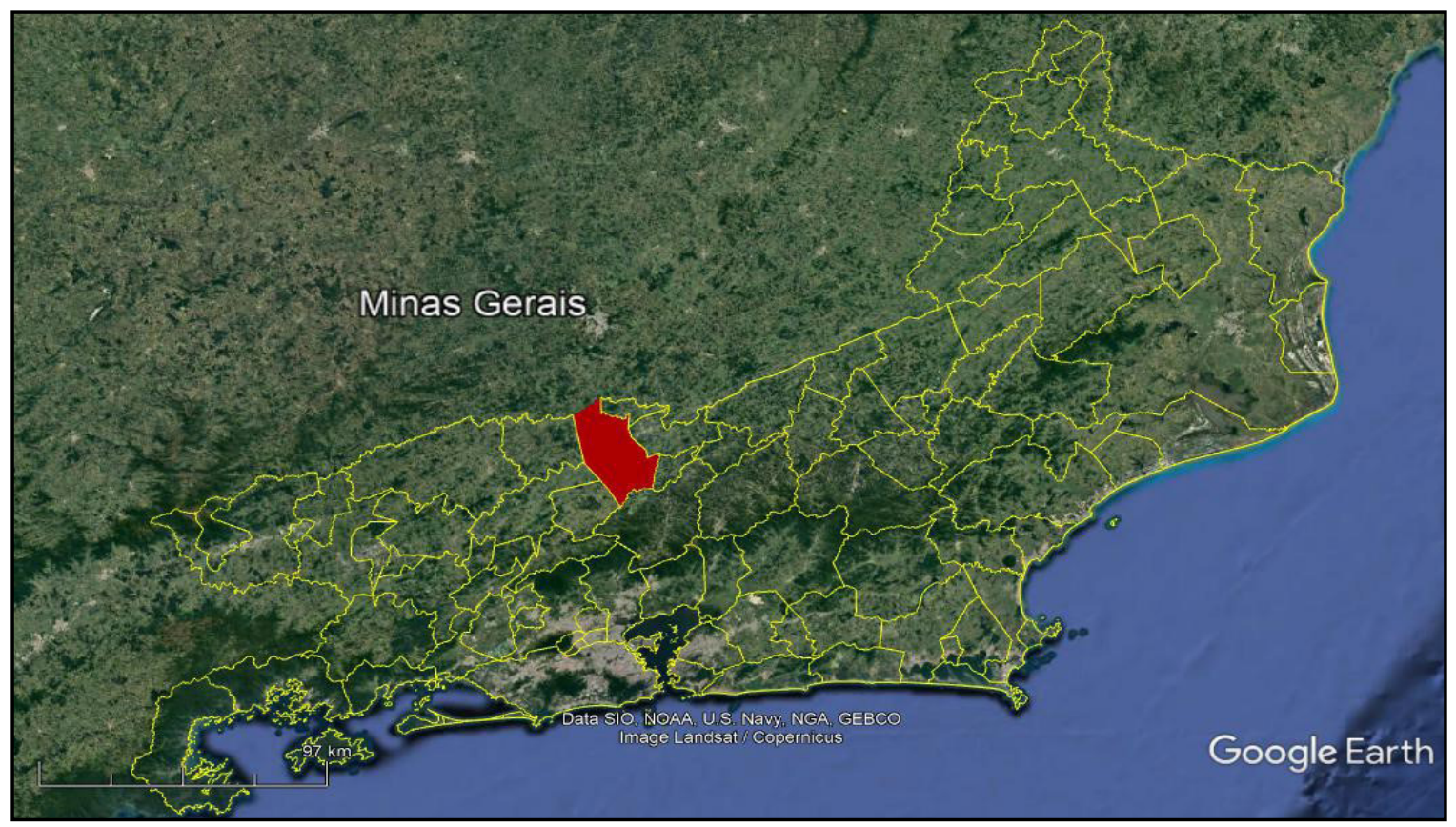

Fonte: Google Earth (2019) - com adaptações

\section{Unidades de conservação sobrepostas à Área de Proteção Ambiental Rainha das Águas}

Além da APA Rainha das Águas, o município de Paraíba do Sul possui mais duas unidades de conservação municipais: Monumento Natural Pedra da Tocaia - MONA Pedra da Tocaia(Decreto N.ำ 1.100 de 2013) e Monumento Natural Monte Cristo - MONA Monte Cristo (Decreto N.ำ 1.099 de 2013) (PARAÍBA DO SUL, 2013a; 2013b; Figura 2). Essas unidades de conservação não possuem plano de manejo, sendo necessário que estes sejam confeccionados para nortear a gestão das unidades e permitir que alcancem os seus importantes objetivos (BRASIL, 2000).

O MONA Monte Cristo foi criado em 2013 com extensão de 1.997 ha (22 $11^{\prime} 7.64 " S$; $43^{\circ} 17^{\prime} 52.73^{\prime \prime O}$ ) (PARAÍBA DO SUL, 2013a). Essa unidade de conservação apresenta fragmentos florestais de tamanho expressivo em comparação com os demais presentes na região, além de possuir aspectos peculiares, como fazendas históricas e pequenas cachoeiras que valorizam sua beleza cênica. O Monumento Natural se enquadra no grupo de unidades de conservação de proteção integral, ou seja, é mais restritivo que a APA quanto ao uso e ocupação da área. Nessa categoria de unidade de conservação é permitida a visitação e, a princípio, não permite o uso direto dos recursos naturais, embora existam exceções (BRASIL, 2000; ALMEIDA; VARGAS, 2017). Os objetivos do MONA Monte Cristo são: "I - Preservar a beleza cênica e ecológica da Serra das Abóboras; II - Proteger ecossistemas com grande potencial para oferecer oportunidades de visitação, aprendizagem, interpretação, educação, pesquisa, recreação, inspiração, relaxamento e atividades espirituais ambientalmente compatíveis; III - Estimular o turismo e a geração de 
emprego e renda" (PARAÍBA DO SUL, 2013a).

O MONA Pedra da Tocaia $\left(22^{\circ} 11^{\prime} 9.40^{\prime \prime}\right.$; $\left.43^{\circ} 17^{\prime} 52.73^{\prime \prime O}\right)$ possui área de 257 ha e foi criado em 2013 (PARAÍBA DO SUL, 2013b). Possui os objetivos a seguir: "I - Preservar a beleza cênica e ecológica da Pedra da Tocaia e todo seu entorno; II - Proteger ecossistemas com grande potencial para oferecer oportunidades de visitação, aprendizagem, interpretação, educação, pesquisa, recreação, inspiração, relaxamento e atividades espirituais ambientalmente compatíveis; III Estimular o turismo e a geração de emprego e renda" (PARAÍBA DO SUL, 2013b).

Figura 2 - Localização do Monumento Natural Pedra da Tocaia (vermelho) e do Monumento Natural Monte Cristo (amarelo) na Área de Proteção Ambiental Rainha das Águas (verde), Município de Paraíba do Sul, Estado do Rio de Janeiro, Brasil

Figure 2 - Location of the Pedra da Tocaia Natural Monument (red) and Monte Cristo Natural Monument (yellow) within the Rainha das Águas Environment Protection Area (green), municipality of Paraíba do Sul, state of Rio de Janeiro, Brazil

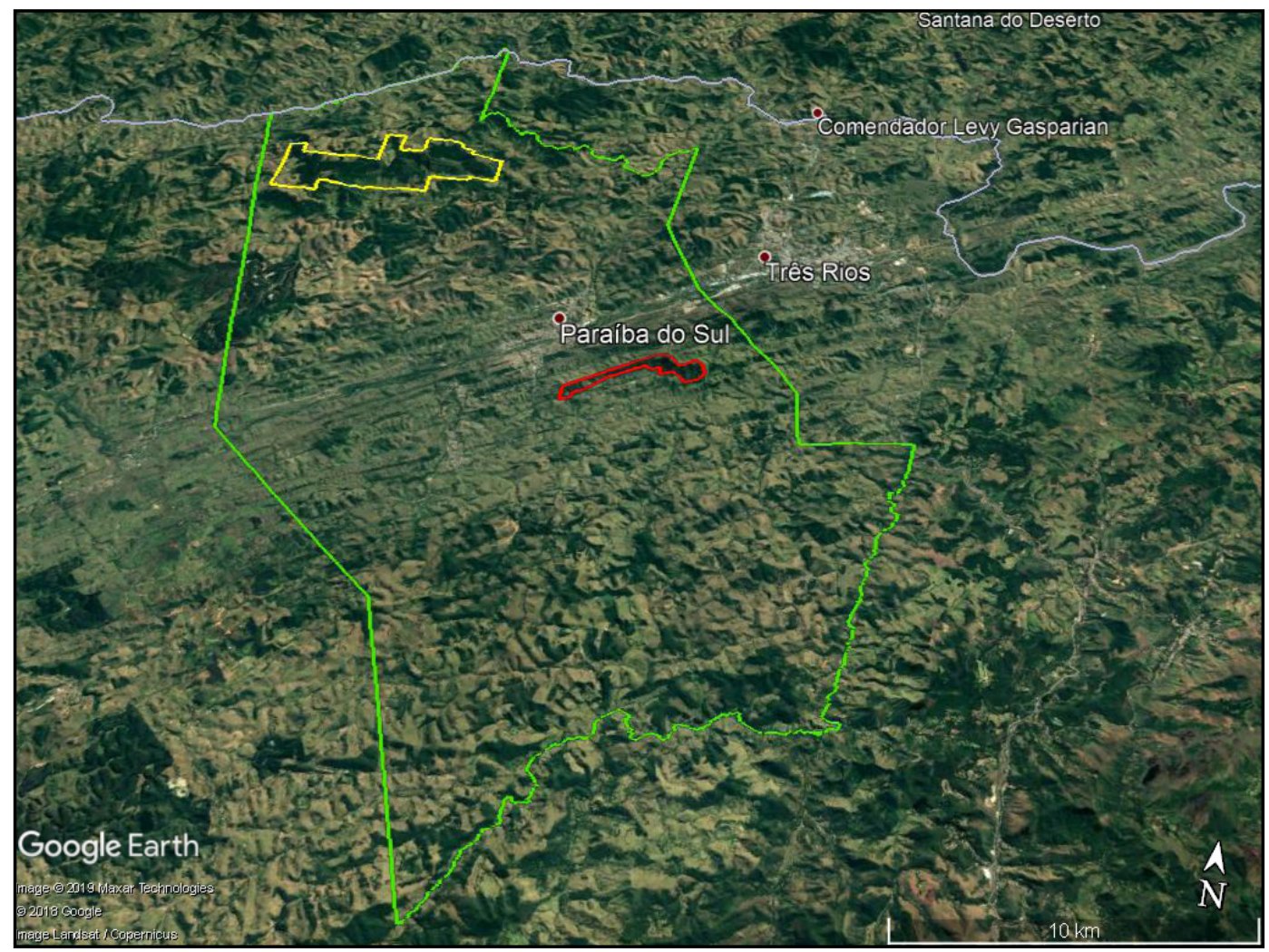

Fonte: Google Earth (2019) - com adaptações

Além das unidades de conservação municipais, a APA Rainha das Águas também é sobreposta por uma unidade de conservação estadual, o Refúgio de Vida Silvestre Estadual do Médio Paraíba (Decreto n. 45.659 de 2016), categoria que possui o intuito de preservar e garantir a reprodução de espécies da fauna e flora local e migratória, estando classificada também no grupo de proteção integral(BRASIL, 2000). Os objetivos do REVIS do Médio Paraíbaincluem "I Assegurar a preservação dos remanescentes de Mata Atlântica e ecossistemas associados ao rio Paraíba do Sul, bem como recuperar as áreas degradadas ali existentes; II - Manter populações de animais e plantas nativas e oferecer refúgio para espécies migratórias, raras, vulneráveis, endêmicas e ameaçadas de extinção da fauna e flora nativas" (RIO DE JANEIRO, 2016). 


\section{Resultados e discussão}

\section{Cobertura Florestal da APA Rainha das Águas}

Foram detectados ao todo 612 fragmentos florestais ao longo da APA, sendo de 23,01\% a porcentagem de cobertura florestal (Figura 3). Segundo Silvério Neto (2014), o município passou por expressivas mudanças em sua paisagem a partir do ciclo do café, quando extensas áreas de florestas foram derrubadas para a implantação dessa cultura, sendo seguido da implantação de outros cultivos agrícolas e, principalmente, de pastagens para a criação de gado, também ocorrendo a expansão de áreas urbanas, processos que comprometeram os recursos naturais da região e colocam em risco a biodiversidade nativa.

O distrito de Paraíba do Sul apresenta a maior quantidade de fragmentos florestais e o distrito de Werneck possui o menor número de remanescentes (Tabela 1). A maior porcentagem de área coberta por florestas nativas também é observada no distrito Paraíba do Sul. Assim, existem porções da APA Rainha das Águas com maior propensão a manter a biodiversidade nativa e a qualidade dos recursos naturais, também podem oferecer melhores oportunidades de uso público, como o turismo ecológico. Por outro lado, os resultados também indicam que parcelas da unidade de conservação requerem medidas de recuperação ambiental ou podem ser indicadas, via zoneamento, como áreas destinadas a atividades produtivas, como a agricultura, a pecuária ou atividades industriais, ou mesmo constituindo-se em áreas urbanas. Desse modo, a distribuição dos ecossistemas naturais da APA Rainha das Águas é relevante para o seu zoneamento.

Figura 3 - Mapa de uso e cobertura do solo dos distritos presentes na Área de Proteção Ambiental Rainha das Águas, no Município de Paraíba do Sul, Estado do Rio de Janeiro, Brasil

Figure 3 - Map of land use and land cover of the districts comprising the Rainha das Águas Environment Protection Area, in the municipality of Paraíba do Sul, state of Rio de Janeiro, Brazil

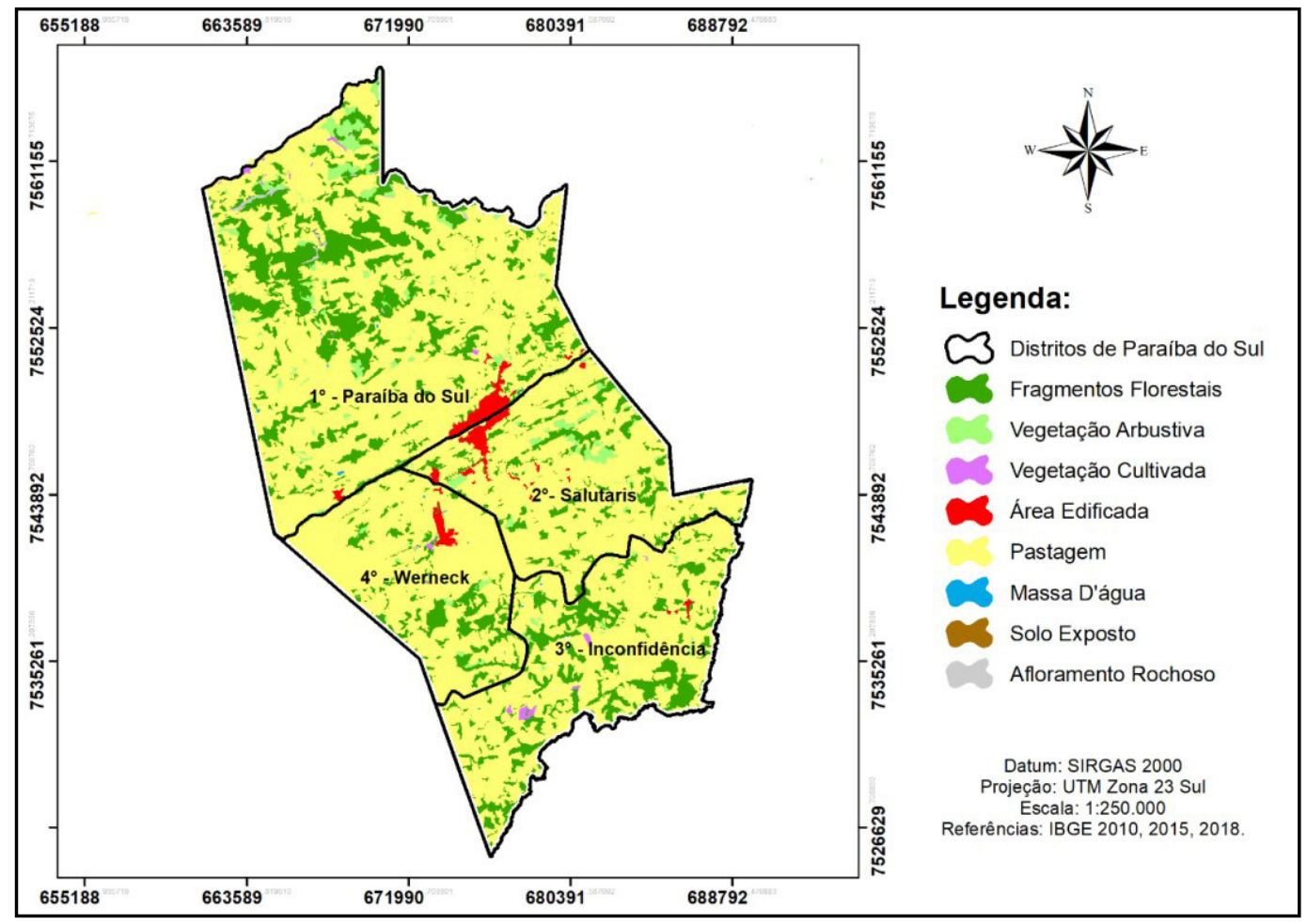

Fonte: Autores (2019) 
Tabela 1 - Área total, área com cobertura florestal, porcentagem de cobertura florestal e número de fragmentos florestais nos distritos presentes na Área de Proteção Ambiental Rainha das Águas, Município de Paraíba do Sul, Estado do Rio de Janeiro, Brasil

Table 1 - Total area, forest cover area, percentage of forest cover, and number of forest fragments in the districts comprising the Rainha das Águas Environment Protection Area, municipality of Paraíba do Sul, state of Rio de Janeiro, Brazil

\begin{tabular}{lcccc}
\hline \multicolumn{1}{c}{ Variáveis } & Paraíba do Sul & Salutaris & Inconfidência & Werneck \\
\hline Área Total (ha) & 26.369 & 10.200 & 11.898 & 8.603 \\
Área com Cobertura Florestal (ha) & 6.883 & 1.746 & 3.047 & 1.498 \\
Porcentagem de Cobertura Florestal (\%) & 26,10 & 17,12 & 25.61 & 17,41 \\
Número de Fragmentos florestais & 294 & 138 & 115 & 108 \\
\hline
\end{tabular}

Fonte: Autores (2019)

Em sua maioria, os fragmentos florestais em todos os distritos presentes na APA Rainha das Águas são pequenos (Tabela 2), o que é problemático para a conservação da biodiversidade da unidade de conservação, além de por em risco os serviços ecossistêmicos. Fragmentos florestais de pequeno tamanho não suportam populações viáveis de diversos grupos taxonômicos, incluindo predadores de topo de cadeia alimentar e outras espécies de animais que apresentam extensa área de vida (home range) (PRIMACK; RODRIGUES, 2001). Tais espécies frequentemente apresentam grande porte, mas espécies de pequeno porte que precisam de condições ambientais específicas também podem ser negativamente afetadas pela redução da área dos habitats. A perda de biodiversidade se reflete em prejuízos no que tange os serviços ecossistêmicos, como a polinização de espécies agrícolas e o controle biológico de pragas (ALMEIDA; VARGAS, 2017).

O elevado nível de isolamento de alguns dos fragmentos florestais também é preocupante (Tabela 3), pois reduz o fluxo gênico e aumenta a perda de diversidade genética (PRIMACK; RODRIGUES, 2001). É possível verificar que grande parcela da área da APA Rainha das Águas apresenta pastagens, sendo essa a principal feição da paisagem que isola os fragmentos florestais.

Tabela 2 - Número de fragmentos florestais por classe de tamanho nos distritos presentes na Área de Proteção Ambiental Rainha das Águas, Município de Paraíba do Sul, Estado do Rio de Janeiro, Brasil

Table 2 - Number of forest fragments by size class in the districts comprising the Rainha das Águas Environment Protection Area, municipality of Paraíba do Sul, state of Rio de Janeiro, Brazil

\begin{tabular}{lcccc}
\hline \multicolumn{1}{c}{ Área $($ ha) } & Paraíba do Sul & Salutaris & Inconfidência & Werneck \\
\hline $\mathbf{0 , 0}-\mathbf{5 , 0}$ & 142 & 75 & 35 & 66 \\
$\mathbf{5 , 1}-\mathbf{1 0 , 0}$ & 60 & 18 & 32 & 22 \\
$\mathbf{1 0 , 1}-\mathbf{5 0 , 0}$ & 74 & 40 & 38 & 16 \\
$\mathbf{5 0 , 1}-\mathbf{1 0 0 , 0}$ & 9 & 3 & 8 & 2 \\
$\mathbf{1 0 0 , 1}-\mathbf{2 0 0 , 0}$ & 3 & 2 & 2 & 2 \\
$>\mathbf{2 0 0 , 0}$ & 6 & 0 & 2 & 1 \\
\hline
\end{tabular}

Fonte: Autores (2019) 
Tabela 3 - Número de fragmentos florestais por classe de isolamento nos distritos presentes na Área de Proteção Ambiental Rainha das Águas, Município de Paraíba do Sul, Estado do Rio de Janeiro, Brasil

Table 3 - Number of forest fragments by isolation class in the districts present in the Rainha das Águas Environment Protection Area, municipality of Paraíba do Sul, state of Rio de Janeiro, Brazil

\begin{tabular}{lcccc}
\hline Isolamento $(\mathbf{m})$ & Paraíba do Sul & Salutaris & Inconfidência & Werneck \\
\hline $\mathbf{0 0 , 0}-\mathbf{5 0 , 0}$ & 132 & 74 & 40 & 63 \\
$\mathbf{5 0 , 1}-\mathbf{1 0 0 , 0}$ & 74 & 21 & 32 & 15 \\
$\mathbf{1 0 0 , 1}-\mathbf{2 0 0 , 0}$ & 45 & 25 & 29 & 19 \\
$\mathbf{2 0 0 , 1}-\mathbf{3 0 0 , 0}$ & 16 & 7 & 10 & 6 \\
$>\mathbf{3 0 0 , 0}$ & 27 & 11 & 4 & 5 \\
\hline
\end{tabular}

Fonte: Autores (2019)

Uma pequena porcentagem do total de remanescentes florestais existentes da APA Rainha das Águas apresenta índice de circularidade próximo de 1, assim uma elevada parcela dos fragmentos florestais da APA sofre expressivo efeito de borda (Tabela 4).O aumento do efeito de borda ocorre como resultado da fragmentação das florestas, pois as condições ambientais nos trechos marginais são diferentes daqueles observados no interior dos remanescentes florestais e essas mudanças nos atributos ambientais afetam a biota presente nas bordas das florestas (SILVA et al., 2017).

Tabela 4 - Número de fragmentos florestais por classe de índice de circularidade nos distritos presentes na Área de Proteção Ambiental Rainha das Águas, Município de Paraíba do Sul, Estado do Rio de Janeiro, Brasil

Table 4 - Number of forest fragments by circularity index class, in the districts comprising the Rainha das Águas Environment Protection Area, municipality of Paraíba do Sul, state of Rio de Janeiro, Brazil

\begin{tabular}{lcccc}
\hline Classes de índice de circularidade & Paraíba do Sul & Salutaris & Inconfidência & Werneck \\
\hline $\mathbf{0 , 0}-\mathbf{0 , 4}$ & 48 & 36 & 27 & 20 \\
$\mathbf{0 , 4}-\mathbf{0 , 6}$ & 122 & 54 & 48 & 41 \\
$\mathbf{0 , 6}-\mathbf{0 , 8}$ & 104 & 41 & 36 & 35 \\
$>\mathbf{0 , 8}$ & 20 & 7 & 4 & 12 \\
\hline
\end{tabular}

Fonte: Autores (2019)

\section{Problemas para a gestão e programas de manejo}

Dentre os problemas identificados na APA Rainha das Águas, o desmatamento é um dos mais graves, pois está associado à reduzida cobertura florestal e elevada fragmentação dos remanescentes (Tabela 5). A redução dos habitats reflete na redução de recursos para a biota, como abrigo e alimento, o que diminui o tamanho populacional das diferentes espécies, gera perda de diversidade genética e aumento da endogamia (PRIMACK; RODRIGUES, 2001; ALMEIDA; 
VARGAS, 2017). O isolamento das populações também está associado à redução da variabilidade genética e aumento do cruzamento entre parentes próximos, o que gera a depressão endogâmica (PRIMACK; RODRIGUES, 2001). A redução dos habitats é apontada, em todo o mundo, como uma das principais causas de extinção de espécies e é temerário que extinções locais possam estar ocorrendo na APA Rainha das Águas. A redução e fragmentação florestal aumentam a incidência do efeito de borda, onde a borda das florestas apresenta condição ambiental diferente do seu interior, o que também influencia negativamente diversas espécies (PRIMACK; RODRIGUES, 2001; ALMEIDA; VARGAS, 2017). As queimadas são comuns na APA Rainha das Águas e resultam em redução de cobertura florestal e de populações de espécies da fauna e flora, além de causar impactos negativos para o solo, pois diminuem a fertilidade, podem por em risco os cidadãos que habitam a APA e seus bens materiais.

\section{Tabela 5 - Problemas para a gestão da Área de Proteção Ambiental Rainha das Águas e principais consequências negativas associadas}

Table 5 - Problems for the management of the Rainha das Águas Environment Protection Area and the main negative consequences associated

\begin{tabular}{|c|c|}
\hline Problemas/Contingências & Principais Consequências \\
\hline $\begin{array}{l}\text { Desmatamento e } \\
\text { queimadas }\end{array}$ & $\begin{array}{c}\text { Redução da área com habitats nativos, fragmentação florestal, isolamento de } \\
\text { populações bióticas, redução da biodiversidade, degradação do solo, degradação de } \\
\text { recursos hídricos }\end{array}$ \\
\hline $\begin{array}{l}\text { Caça, pesca predatória e } \\
\text { coleta de plantas nativas }\end{array}$ & Redução de populações bióticas, perda de biodiversidade, desequilíbrio ecológico. \\
\hline $\begin{array}{l}\text { Construções em locais } \\
\text { inapropriados }\end{array}$ & $\begin{array}{l}\text { Aumento da ocorrência de acidentes, prejuízos financeiros, perda de vidas } \\
\text { humanas }\end{array}$ \\
\hline $\begin{array}{l}\text { Agropecuária e } \\
\text { silvicultura realizadas de } \\
\text { forma imprópria }\end{array}$ & $\begin{array}{l}\text { Poluição ambiental, perda de biodiversidade, incidência de doenças, degradação do } \\
\text { solo, degradação de recursos hídricos }\end{array}$ \\
\hline $\begin{array}{l}\text { Poluição por efluentes } \\
\text { líquidos }\end{array}$ & $\begin{array}{l}\text { Contaminação de recursos hídricos, perda de biodiversidade, incidência de } \\
\text { doenças, redução da disponibilidade de água para consumo humano }\end{array}$ \\
\hline $\begin{array}{l}\text { Introdução de espécies } \\
\text { exóticas }\end{array}$ & Redução de populações bióticas e perda de biodiversidade nativa \\
\hline $\begin{array}{l}\text { Falta de conhecimento da } \\
\text { população sobre a APA }\end{array}$ & $\begin{array}{l}\text { Baixa participação da população na gestão, proteção (fiscalização) e na } \\
\text { implementação da APA.Baixo aproveitamento das potencialidades da unidade de } \\
\text { conservação }\end{array}$ \\
\hline $\begin{array}{l}\text { Escassez de conhecimento } \\
\text { sobre a biodiversidade da } \\
\text { APA }\end{array}$ & $\begin{array}{l}\text { Probabilidade de extinção local de espécies em função da não existência de ações } \\
\text { preservacionistas dirigidas especificamente às espécies ameaçadas. }\end{array}$ \\
\hline $\begin{array}{l}\text { Escassez de recursos } \\
\text { financeiros }\end{array}$ & $\begin{array}{l}\text { Dificuldades para implementar as ações necessárias para a correta gestão da APA } \\
\text { Rainha das Águas. }\end{array}$ \\
\hline
\end{tabular}

Fonte: Autores (2019)

Como medidas de manejo para reverter esse quadro, sugere-se que sejam realizados reflorestamentos em locais prioritários, principalmente formando corredores ecológicos e para reduzir o efeito de borda nos fragmentos florestais (Tabela 6). Os reflorestamentos devem ser realizados prioritariamente nos distritos de Salutaris e Werneck, pois são os que apresentam menor cobertura florestal. Todavia, os demais distritos também possuem considerável número 
de fragmentos florestais pequenos e isolados, também carecendo de reflorestamentos planejados para otimizar a conservação ambiental. Também sugere-se a utilização da educação ambiental e da fiscalização contra queimadas e a supressão ilegal da vegetação. A educação ambiental pode ser voltada para agricultores e pecuaristas, pois elevado número de queimadas se iniciam em áreas agrícolas e pastagens, mas também é importante conscientizar o restante da população, até mesmo pelo fato de elevada parcela dos incêndios florestais ser causada por incendiários (TORRES et al., 2016).Os recursos advindos da compensação ambiental de empresas que venham a se instalar ou que já estejam instaladas em Paraíba do Sul podem ser direcionados para a execução das atividades citadas acima.

\section{Tabela 6 - Problemas para a gestão da Área de Proteção Ambiental Rainha das Águas e medidas de manejo para reduzir os problemas detectados}

Table 6 - Problems for the management of the Rainha das Águas Environment Protection Area and management actions to reduce those problems

\begin{tabular}{|c|c|}
\hline Problemas/Contingências & Medidas de Manejo \\
\hline $\begin{array}{l}\text { Desmatamento e } \\
\text { queimadas }\end{array}$ & $\begin{array}{l}\text { Reflorestamento, educação ambiental, fiscalização contra a supressão ilegal da } \\
\text { vegetação e compensação ambiental. }\end{array}$ \\
\hline $\begin{array}{l}\text { Caça, pesca predatória e } \\
\text { coleta de plantas nativas }\end{array}$ & $\begin{array}{l}\text { Educação ambiental, fiscalização, estímulo a denuncias, estimular a criação legal das } \\
\text { espécies caçadas, estímulo ao cultivo das espécies de plantas coletadas. }\end{array}$ \\
\hline $\begin{array}{l}\text { Construções em locais } \\
\text { inapropriados }\end{array}$ & $\begin{array}{l}\text { Planejamento e fiscalização para disciplinar o uso e ocupação do solo, visando o } \\
\text { desenvolvimento sustentável na APA. }\end{array}$ \\
\hline $\begin{array}{l}\text { Agropecuária e } \\
\text { silvicultura realizadas de } \\
\text { forma imprópria }\end{array}$ & $\begin{array}{l}\text { Educação ambiental, estímulo à adoção de policultivos e práticas agroecológicas, } \\
\text { estímulo a adoção de pastagens sombreadas, correto uso e descarte de material. } \\
\text { Parcerias paraimplementação de curso de capacitação dos produtores. }\end{array}$ \\
\hline $\begin{array}{l}\text { Poluição por efluentes } \\
\text { líquidos }\end{array}$ & Tratamento de efluentes residenciais e industriais, fiscalização. \\
\hline $\begin{array}{l}\text { Introdução de espécies } \\
\text { exóticas }\end{array}$ & $\begin{array}{l}\text { Educação para que moradores evitem que animais domesticados adentrem } \\
\text { ecossistemas naturais, programas de manejo de fauna exótica. }\end{array}$ \\
\hline $\begin{array}{l}\text { Escassez de conhecimento } \\
\text { sobre a biodiversidade da } \\
\text { APA }\end{array}$ & Estimular a realização de pesquisas científicas na APA. \\
\hline $\begin{array}{l}\text { Falta de conhecimento da } \\
\text { população sobre a APA }\end{array}$ & $\begin{array}{c}\text { Disseminaras informações necessárias para que a população conheça a unidade e } \\
\text { seus atrativos, via websites, rádios e jornais locais, reuniões formais, e outras formas } \\
\text { de comunicação. }\end{array}$ \\
\hline $\begin{array}{l}\text { Escassez de recursos } \\
\text { financeiros }\end{array}$ & $\begin{array}{l}\text { Obtenção de recursos via ICMS Ecológico, compensação ambiental, produtos e } \\
\text { serviços inerentes à APA }\end{array}$ \\
\hline
\end{tabular}

Fonte: Autores (2019)

Outro problema comumente observado para a conservação da diversidade biológica em unidades de conservação é a superexploração dos componentes da biota nativa, via caça de animais silvestres e a extração de espécimes vegetais (ALMEIDA; VARGAS,2017). A caça é historicamente apontada como uma das causas da extinção de espécies de vários táxons, especialmente aves e mamíferos, em várias partes do mundo (PRIMACK; RODRIGUES,2001). A caça de aves e mamíferos é comum em várias regiões do Brasil, incluindo em unidades de conservação (ARAÚJO et al., 2008). Com o desaparecimento das espécies, processos ecológicos vitais para a manutenção do equilíbrio dos ecossistemas são ameaçados e também são perdidos serviços ambientais benéficos para as atividades antrópicas (ALMEIDA; VARGAS, 2017). Como 
medidas de manejo para combater a caça e a extração vegetal ilegal e não sustentável, pode-se propor a utilização de um programa de educação ambiental que sensibilize e possa conscientizar a população dos problemas ocasionados por essas práticas. A fiscalização também deve ser utilizada para minimizar a superexploração da biodiversidade na APA Rainha das Águas. Além da fiscalização por parte do órgão competente, deve-se haver incentivo para que os habitantes da APA também se tornem agentes fiscalizadores e denunciantes, devido ao reduzido corpo técnico por vezes presente no órgão municipal gestor da unidade de conservação. A criação de pássaros é bastante comum na região e, para reduzir a captura de aves nativas, sugere-se uma campanha para estimular a criação legalizada dessas aves com a reprodução em cativeiro, pois essa ação pode reduzir a pressão de caça. Existem criadores amadores de passeriformes legalizados no Sistema de Controle e Monitoramento da Atividade de Criação Amadora de Pássaros -SISPASS/ IBAMA - Instituto Brasileiro do Meio Ambiente e dos Recursos Naturais Renováveis.

Além da caça de animais terrestres, a pesca predatória e, principalmente, em época de piracema pode causar sérios prejuízos para a biodiversidade nativa e, até mesmo, para a população local (ALVES, 2019). Existem evidências de que a pesca predatória ocorre com frequência na região da APA Rainha das Águas (ALVES, 2019). As medidas para reduzir a pesca predatória são basicamente as mesmas citadas anteriormente, ou seja, adotar práticas de educação ambiental e fiscalização.

Nas APAs é comum ocorrer o inadequado uso e ocupação do solo, inclusive com a construção de moradias em locais com risco de desmoronamento e inundações, e como um dos objetivos das APAs é disciplinar o uso e ocupação do solo (ALMEIDA; VARGAS, 2017), deve-se realizar o levantamento de construções ou de áreas cultivadas que estão em locais inapropriados, como em Áreas de Preservação Permanente (APP), e estudar a possibilidade de reassentamento da população e/ou mudança do uso do solo, conforme o caso. Sobretudo, é necessário evitar que áreas com risco a inundações, áreas muito íngremes ou protegidas pela legislação sejam ocupadas de forma inadequada, ocorrendo prioritariamente a prevenção.

Grande porção da APA Rainha das Águas é ocupada por atividades agropecuárias, ocorrendo principalmente pastagens. Nota-se que essas pastagens possuem geralmente baixo número de bovinos e podem não estar sendo corretamente manejadas, pois algumas áreas apresentam indícios de expressiva erosão do solo. Assim, é necessário repensar o uso dessas áreas ou as práticas utilizadas na criação do gado. As atividades agrícolas e a pecuária extensiva, principalmente se realizadas de forma inapropriada, podem gerar impactos, como a poluição da água e degradação do solo, pelos agrotóxicos utilizados e pelos processos erosivos, por exemplo (ALMEIDA et al., 2017). Também ocorrem impactos negativos sobre a biodiversidade, a saúde da população e a sustentabilidade das atividades econômicas, incluindo a própria produção agropecuária (ALMEIDA et al., 2017). Os programas de manejo podem incluir campanhas educativas para a adoção de práticas produtivas menos danosas ao meio ambiente, incluindo os policultivos, os sistemas agroflorestais, as pastagens sombreadas, que pode ser entendida como um tipo de sistema agroflorestal, os métodos agroecológicos e a agricultura orgânica. Essas práticas, além de serem úteis para minimizar impactos ambientais negativos sobre componentes do meio físico e biológico, também podem ajudar a diversificar e aumentar a produção agropecuária, tornando ainda essa produção mais sustentável.

As residências e indústrias locais ocasionam o lançamento de efluentes líquidos nos rios da APA Rainha das Águas. Essa poluição ameaça a diversidade biológica e também a qualidade de água para o abastecimento público (ALVES,2019). Visto que o rio Paraíba do Sul perpassa vários municípios antes de chegar a APA, a carga de poluentes acumulada pode ser bastante expressiva. Como medidas sugeridas estão a captação e o tratamento desses efluentes residenciais e industriais. A fiscalização também deve ser utilizada para o combate da poluição industrial.

Nas unidades de conservação com expressiva ocupação humana é comum ter ocorrido a introdução de espécies exóticas nos ecossistemas locais, espécies exóticas que podem competir ou predar espécies nativas, reduzindo as suas populações e podendo levar as espécies nativas à 
extinção local (PRIMACK; RODRIGUES, 2001). Espécies podem ser introduzidas acidentalmente, serem levadas propositalmente para fins econômicos ou serem criadas como animais de estimação. Como exemplo, Galetti e Sazima (2006) constataram que cães ferais domésticos abatem um elevado número de espécies nativas em florestas de Mata Atlântica. Assim, até mesmo cães e gatos domésticos são ameaças em potencial para as espécies nativas na APA Rainha das Águas e devem ser tomadas medidas para reduzir o impacto negativo das espécies exóticas sobre a biodiversidade nativa. A educação ambiental deve ser adotada para reduzir a introdução de espécies exóticas nos ecossistemas naturais da APA. Deve-se sensibilizar os moradores locais para evitar que animais domesticados (gado, cães e gatos) adentrem ecossistemas naturais, como as florestas nativas presentes na APA. No caso da espécie exótica se tornar uma clara ameaça às espécies nativas da APA, os gestores da unidade de conservação podem buscar a erradicação da espécie invasora, principalmente não se tratando de espécie domesticada.

As informações sobre a biodiversidade de Paraíba do Sul são bastante escassas, mas segundo Roussouliéres (2015) já foi registrada a ocorrência de 215 espécies de aves, incluindo espécies classificadas como quase ameaçadas de extinção, vulneráveis ou em perigo(ROUSSOULIÉRES, 2015).Soares (2018) constatou o registro de apenas cinco espécies de peixes no Município de Paraíba do Sul, o que destaca a necessidade de levantamentos de espécies de vários grupos taxonômicos. Embora tenham sido realizados levantamentos de espécies de peixes em outros trechos do rio Paraíba do Sul, é necessário ampliar consideravelmente o conhecimento sobre a ictiofauna no município. Soares (2018) também relatou o registro de artrópodes em Paraíba do Sul, porém desse grupo taxonômico foram geradas listas de espécies apenas para Hymenoptera, principalmente formigas (Formicidae). Já Estrada et al. (2019) coletaram 48 espécies de formigas em áreas cultivadas na APA Rainha das Águas, sem a indicação de espécies ameaçadas de extinção. No Município de Três Rios, município vizinho de Paraíba do Sul, houve o registro de espécies arbóreas, de mamíferos e de aves ameaçadas de extinção(RIMA CTR TRÊS RIOS, 2014) e tais espécies, assim como várias outras espécies ameaçadas de extinção, podem ocorrer na APA Rainha das Águas, embora ainda não tenham sido registradas na unidade de conservação.

É comum que a população que reside em unidades de conservação recentemente criadas tenha pouco conhecimento sobre a unidade de conservação, incluindo o conhecimento sobre os objetivos, potencialidades e restrições da área protegida. É importante que os cidadãos que residem na APA colaborem com a gestão da unidade de conservação e para tal é essencial que tenham informações sobre as diretrizes da APA. O programa de comunicação é utilizado para informar a população sobre as unidades de conservação (BENTO, 2014), devendo-se utilizar todos os meios de comunicação disponíveis para informar a população, incluindo a utilização de websites, reuniões formais, rádios e jornais locais. Os gestores da APA devem disseminar as informações necessárias para que a população conheça a unidade e seus atrativos, como os pontos turísticos.

Para implementar as medidas de manejo da APA Rainha das Águas, pode ser utilizado parte do valor arrecadado com o ICMS Ecológico, visto que parcela do valor obtido pelos municípios deve-se a presença de unidades de conservação no seu território e que as unidades de conservação municipais propiciam o recebimento de maiores valores de ICMS Ecológico (BENTO, 2014). A captação de recursos via compensação ambiental também é uma importante fonte de divisas para as unidades de conservação (BENTO, 2014). Além disso, pode-se buscar a obtenção de recursos via oferta de produtos e serviços da APA Rainha das Águas, principalmente associados aos atrativos turísticos.

\section{Potencialidades para a gestão}

A APA Rainha das Águas apresenta diversos locais com atrativos turísticos, que podem ser explorados de variadas formas. Assim, deve-se divulgar amplamente os pontos turísticos já existentes e trabalhar para o aproveitamento das potencialidades ainda não exploradas. É 
necessário planejar a recepção de turistas, de modo a gerar emprego e renda e captar recursos para a gestão da unidade de conservação. Os moradores da APA Rainha das Águas podem receber treinamento e serem incentivados a atuar no turismo e em outras atividades relacionadas ao uso público da APA, comércio de produtos locais e oferta de serviços. Cabe destacar que esse processo, caso conduzido com o cuidado de trabalhar com a população de baixa renda, pode acarretar em inclusão social, além de gerar o sentimento de valoração dos bens naturais e culturais locais.

O Parque das Águas Minerais Salutares apresenta atrativos turísticos, com oportunidades para práticas esportivas, lazer em contato com a natureza, trilhas ecológicas, belas paisagens e atrativos históricos. Pessoas também visitam o parque para a captação de água mineral nas fontes presentes no local. Deve-se buscar a intensificação das atividades realizadas no Parque Salutares, promover eventos que possibilitem debates relacionados ao meio ambiente e estimulem a conservação ambiental, pois o parque oferece oportunidades para práticas de educação ambiental. Produtos e serviços da APA Rainha das Águas podem ser oferecidos aos frequentadores do parque, gerando divisas para a gestão da unidade de conservação.

A praça Marquês de São João Marcos (Jardim Velho) está inserida na área de abrangência do centro histórico de Paraíba do Sul(PARAÍBA DO SUL, 2006). Trata-se de um local bastante frequentado pelos habitantes locais e turistas, por possuir diferentes atrativos para o lazer, além de atrativos culturais. Apresenta beleza cênica, com jardim característico do romantismo inglês, com o coreto construído em 1908 localizado no centro da praça, sendo tombado pelo Instituto Estadual do Patrimônio Cultural (INEPAC)(PARAÍBA DO SUL, 2019).Nas proximidades da praça encontra-se a estação ferroviária de Paraíba do Sul, que foi inaugurada no ano de 1867. No ano de 2003 passou por uma reforma e começou a funcionar como linha turística, porém suas atividades foram encerradas. A reativação dessa linha pode ser útil para a atração de turistas. Além disso, um museu ferroviário também foi construído e permanece em funcionamento (ROUSSOULIÉRES, 2015). Outro ponto turístico relevante é o Museu Sacro Histórico de Tiradentes, onde supostamente estão expostos restos mortais do inconfidente Joaquim José da Silva Xavier, o Tiradentes (ROUSSOULIÉRES, 2015).Tendo em vista a rica história de Paraíba do Sul, o turismo histórico pode ser incentivado, com visitas, por exemplo, ao Museu Tiradentes e à Estação Ferroviária de Paraíba do Sul.

Visitas ao MONA Pedra da Tocaia e ao MONA Monte Cristo também devem ser incentivadas. Além do interesse pelas belas paisagens e características peculiares (a Pedra da Tocaia possui aproximadamente $700 \mathrm{~m}$ de altura), também possuem valor histórico. Como exemplo, a Pedra da Tocaia recebeu essa denominação por ser usada pelos bandeirantes para monitorar o território do município(ROUSSOULIÉRES, 2015). Além disso, como uma oportunidade de implementação de turismo ecológico, o rio Paraíba do Sul pode ser aproveitado para a execução de atividades esportivas, como o rafting e passeios em embarcações.

O Município de Paraíba do Sul também apresenta propriedades rurais onde ocorre a produção de produtos orgânicos. Esses cultivos podem ser aproveitados para incentivar que outros agricultores existentes na APA adotem esse sistema de cultivo, abandonando a utilização de defensivos agrícolas químicos sintéticos expressivamente nocivos ao meio ambiente. Pode-se ainda buscar realizar o turismo rural, tendo como foco a visita de turistas às propriedades com cultivos orgânicos. Assim como propiciar cursos para capacitar os produtores sobre o modo de cultivo, venda e logística sustentável.

\section{Conclusão}

Existem diversas ameaças aos bens naturais da APA Rainha das Águas e à população residente, incluindo a redução e fragmentação das florestas nativas, a poluição ambientale a escassez de recursos financeiros para a gestão da unidade. Contudo, a partir da execuçãodas ações de manejo necessárias, incluindo a implementação de reflorestamentos e o uso da fiscalização e da educação ambiental,a APA pode colaborar efetivamente para o desenvolvimento sustentável do Município de Paraíba do Sul. 


\title{
Agradecimentos
}

\author{
À Secretaria Municipal do Ambiente e Desenvolvimento Agrário do Município de Paraíba \\ do Sul.
}

\section{Referências}

ALMEIDA, F. S.; GARRIDO, F. S. R. G.; ALMEIDA, A. A. Avaliação de impactos ambientais: uma introdução ao tema com ênfase na atuação do Gestor Ambiental. Diversidade e Gestão, Três Rios, v. 1, n. 1, p. 70-87, jul. 2017.

ALMEIDA, F. S.; VARGAS, A. B. Bases para a gestão da biodiversidade e o papel do gestor ambiental. Diversidade e Gestão, Três Rios, v. 1, n. 1, p. 10-32, jul. 2017.

ALVES, L. C. Degradação do Rio Paraíba do Sul no Município de Três Rios: causas e consequências. 2019. 55 f. Monografia (Bacharelado em Gestão Ambiental) - Universidade Federal Rural do Rio de Janeiro, Três Rios, 2019.

ARAÚJO, R. M.; SOUZA, M. B.; RUIZ-MIRANDA, C. R. Densidade e tamanho populacional de mamíferos cinegéticos em duas Unidades de Conservação do Estado do Rio de Janeiro, Brasil. Iheringia (Série Zoologia), Porto Alegre, v. 98, n. 3, p. 391-396, set. 2008.

ARRUDA, M. B.; SÁ, L. F. S. N. (org.). Corredores ecológicos: uma abordagem integradora de ecossistemas no Brasil. Brasília: Ibama, 2003. 220 p.

BENTO, M. C. Propostas de manejo para Unidades de Conservação em função de sua cobertura florestal: estudo de caso no Município de Três Rios - RJ. 2014. 30 f. Monografia (Bacharelado em Gestão Ambiental) - Universidade Federal Rural do Rio de Janeiro, Três Rios, 2014.

BORGES, L. F. R.; SCOLFORO, J. R.; OLIVEIRA, A. D.; MELLO, J. M.; ACERBI, F. W.; FREITAS, G. D. Inventário de fragmentos florestais nativos e propostas para seu manejo e o da paisagem. Cerne, Lavras, v. 10, n. 1, p. 22-38, jan./jun. 2004.

BRASIL. Lei No 9.985, de 18 de julho de 2000. Regulamenta o art. 225, §1o, incisos I, II, III e VII da Constituição Federal, institui o Sistema Nacional de Unidades de Conservação da Natureza e dá outras providências. Disponível em: http://www.planalto.gov.br/ccivil_03/leis/ 19985.htm. Acesso em: 08 abr. 2019.

CARDOSO, N. F. S.; GARRIDO, F. S. R. G. Produção, consumo e a evolução da certificação de orgânicos nos municípios de Paraíba do Sul e Três Rios - RJ. Espacios, Caracas, v. 35, n. 12, p. 11, dez. 2014.

CARVALHO, G. O. Sustentabilidade e desenvolvimento sustentável: uma visão contemporânea. Revista Gestão \& Sustentabilidade Ambiental, Florianópolis, v. 8, n. 1, p. 779-792, jan./mar. 2019.

ESTRADA, M. A.; AlmeidA, A. A.; VARGAS, A. B.; AlMEIDA, F. S. Diversidade, riqueza e abundância da mirmecofauna sob cultivo orgânico e convencional. Acta Biológica Catarinense, Joinville, v. 6, n. 2, p. 87-103, abr./jun. 2019.

GALETTI, M.; SAZIMA, I. Impacto de cães ferais em um fragmento urbano de Floresta Atlântica no sudeste do Brasil. Natureza \& Conservação, [s. l.], v. 4, p. 58-63, abr. 2006.

GOOGLE EARTH. Disponível em: https://www.google.com.br/earth/download/gep/agree.html. Acesso em: 13 ago. 2019.

FERNANDES, L. S.; SILVA, S. M. C.; SILVA JUNIOR, L. C.; ACSELRAD, M. V.; PIMENTEL, I. M. C.; FARIAS JUNIOR, J. E. F.; FORMIGA-JOHNSSON, R. M. Águas do Rio: um panorama 
geral da disponibilidade hídrica no Estado fluminense. Revista Ineana, Rio de Janeiro, v. 3, n. 1, jul./dez. 2015.

IBGE. Instituto Brasileiro de Geografia e Estatística. Base cartográfica. Disponível em: https:// www.ibge.gov.br/. Acesso em: 06 out. 2019.

MMA. Ministério do Meio Ambiente. Mata Atlântica. Disponível em: https://mma.gov.br/ component/k2/item/273-mata-at1\%C3\%A2ntica. Acesso em: 26 de out. 2019.

PARAÍBA DO SUL (RJ). Lei no 2.493 de 05 de outubro de 2006. Institui o Plano Diretor de Desenvolvimento Territorial de Paraíba do Sul- PDDT. 2006.

PARAÍBA DO SUL (RJ). Decreto Municipal no 1.099 de 2013. Dispõe sobre a criação Monumento Natural Monte Cristo no município de Paraíba do Sul. 2013a.

PARAÍBA DO SUL (RJ). Decreto Municipal no 1.100 de 2013. Dispõe sobre a criação Monumento Natural Pedra da Tocaia no município de Paraíba do Sul. 2013b.

PARAÍBA DO SUL (RJ). Decreto no 1.323 de 2015. Dispõe sobre a criação da Área de Proteção Ambiental Rainha das Águas do Município de Paraíba do Sul. 2015.

PARAÍBA DO SUL (RJ). Atrações turísticas. Disponível em: http://paraibadosul.rj.gov.br/ turismo/atracoes. Acesso em: 22 de nov. 2019.

PRIMACK, R. B.; RODRIGUES, E. Biologia da conservação. Londrina: Editora Rodrigues, 2001. $327 \mathrm{p}$.

Ribeiro, M. C.; MARTENSEN, A. C.; METZGER, J. P.; TABARELli, M.; SCARANO, F.; FORTIN, M. J. The Brazilian Atlantic Forest: a shrinking biodiversity hotspot. In: ZACHOS, F. E.; HABEL, J. C. (ed.). Biodiversity hotspots: distribution and protection of conservation priority areas. Heidelberg: Springer, 2011. 566 p.

RIMA CTR TRÊS RIOS. Relatório de Impacto ambiental da CTR de Três Rios. 2014. Disponível em: $\quad$ http://www.inea.rj.gov.br/cs/groups/public/documents/document/zwew/mdk1/ edisp/ inea0095944.pdf. Acesso em: 22 nov. 2019.

RIO DE JANEIRO. Decreto no 45.659 de 18 de maio de 2016. Dispõe sobre a criação da unidade de conservação de proteção integral, na categoria refúgio de vida silvestre, denominada Refúgio de Vida Silvestre Estadual do Médio Paraíba. 2016.

ROUSSOUliÉReS, E. G. Proposta de criação da Área de Proteção Ambiental Municipal Rainha das Águas. Programas na SEMAA Paraíba do Sul. Prefeitura de Paraíba do Sul, 2015. 56 p.

SILVA, B. G.; CASTELLO, A. C. D.; KOCH, I.; SILVA, W. R. Pathways affect vegetation structure and composition in the Atlantic Forest in southeastern Brazil. Acta Botanica Brasilica, v. 31, n. 1, p. 108-119, 2017.

SILVÉRIO NETO, R. Caracterização espacial da cobertura florestal dos municípios da Microrregião de Três Rios - RJ. 2014. 37 f. Monografia (Bacharelado em Gestão Ambiental) Universidade Federal Rural do Rio de Janeiro, Três Rios, 2014.

SOARES, B. P. M. Análise do conhecimento atual sobre a fauna da microrregião de Três Rios-RJ e de suas ameaças: um estudo baseado em dados secundários. 2018. 45f. Monografia (Bacharelado em Gestão Ambiental) - Universidade Federal Rural do Rio de Janeiro, Três Rios, 2018.

TORRES, F. T. P.; LIMA, G. S.; COSTA, A. G.; FÉLIX, G. A.; SILVA JÚNIOR, M. R. Perfil dos incêndios florestais em unidades de conservação brasileiras no período de 2008 a 2012. Floresta, Curitiba, v. 46, n. 4, p. 531-542, out./dez. 2016. 